A sociocultural view of sexual assault: From discrepancy to diversity

By: Jacquelyn W. White and Susan B. Sorenson

This is the peer reviewed version of the following article:

White, J.W. \& Sorenson, S.B. (1992) A sociocultural view of sexual assault: From discrepancy to diversity. Journal of Social Issues, 48, 187-195. https://doi.org/10.1111/j.1540-

4560.1992.tb01164.x

which has been published in final form at https://doi.org/10.1111/j.15404560.1992.tb01164.x. This article may be used for non-commercial purposes in accordance with Wiley Terms and Conditions for Use of Self-Archived Versions.

***:C 1992 The Society for the Psychological Study of Social Issues. Reprinted with permission. No further reproduction is authorized without written permission from Wiley. This version of the document is not the version of record. $* * *$

\begin{abstract}
:
Previous analyses of the cultural context of sexual assault have focused on social and demographic correlates of rape, or associations between the acceptance of rape myths and sociocultural beliefs and attitudes. Papers in this journal issue extend this perspective to definitions of rape and characteristics of the research enterprise. They also examine the association between specific sociocultural influences on the reporting of sexual assault, victims' experiences of and reactions to sexual assault, and perpetrator motives, as well as society's responses as reflected in the media and the judicial system. It is concluded that systematic analysis of sociocultural factors allows discrepancies in definitions, methods, results, and interpretations to be reconceptualized as diversity which is orderly and can be understood.
\end{abstract}

Keywords: rape | sexual assault | sociocultural context

\title{
Article:
}

Rape is a highly sensationalized and misunderstood crime in our culture. An April 1991 incident in which William Kennedy Smith, a member of a prominent political family, was charged with rape illustrates the influence of rape myths and attitudes on the attributions of responsibility made by the media. Various tabloids have gone to great lengths to discover the victim's identity, to question her moral integrity by delving into her past sexual history, and to question her motives for filing a rape charge. There is no other crime-murder, burglary, assault and battery-in which the victim is so routinely blamed for the crime. The defense team in the Smith case was expected to challenge Florida's rape shield laws and attempt to put the victim's personal life on trial in order to undermine her credibility (Greensboro News \& Record, 1991). According to the same source, the notoriety of this case has apparently reduced the number of women in Palm Beach County seeking rape exams from ten in the first half of April 1991 to one in the remainder

The authors thank Patricia L. N. Donat and Richard Farmer for comments on an earlier version of this paper. 
of the month. Clearly, society's response to rape accusations has a direct and immediate impact on many women. Similar efforts to blame the victim and to discredit women's accounts of sexual offenses were evident in the U.S. Senate hearings regarding sexual harassment charges leveled at Judge Clarence Thomas during the consideration of his nomination to the Supreme Court.

Cultural attitudes guide the definition, assessment, and study of sexual assault. The public treatment of women who make charges of sexual misconduct, as in the examples cited above, illustrates at least two pervasive cultural beliefs: Victims are blameworthy, and only truly pathological men are capable of rape or other assaultive behaviors. These beliefs also affect the likelihood of victims' reporting sexual assault, and impede both the treatment of victims and the prosecution of perpetrators.

Previous analyses of the cultural context of sexual assault have focused on social and demographic correlates of rape (Jaffe \& Straus, 1987; Sanday, 1981), or on associations between acceptance of rape myths and sociocultural beliefs and attitudes (Burt, 1980; Feild, 1978; Hamey \& Muehlenhard, 1991; Mandoki \& Burkhart, 1991). For example, Jaffe and Straus (1987), using states as the unit of analysis, found positive correlations between levels of reported rape and sex magazine readership, urbanization, poverty, and the percentage of divorced men. They concluded that rape reflects social disorganization and hypermasculine gender roles. Sanday (1981), in a cross-cultural study, suggested that indices of male domination, such as holding political power and frequent warfare, were more characteristic of "rape prone" societies than of "rape free" societies.

The present journal issue extends the sociocultural perspective to definitions of rape and to features of the research enterprise, including specific methodologies to assess the incidence of sexual assault. The analyses offered here also examine the association of specific sociocultural factors (ethnicity, urban/rural locale, the relationship status of the victim and perpetrator) with the reporting of sexual assault, victims' experiences of and reactions to sexual assault, and perpetrator motives. In addition, these papers examine society's responses, specifically those of the media and the judicial system. These analyses suggest that order can be imposed on what appeared to be discrepancies reported in previous research. We are now in a better position to understand these discrepancies in terms of diversity.

Several dimensions underlying previously described discrepancies provide order to the otherwise confusing statistics. Diversity-regarding definitions, methods, ethnicity, geographical regions, and reforms-is a central theme of this volume, and the findings support the premise that rape is a social act. Rape serves social purposes, at both the personal and collective levels (Plummer, 1981). At the personal level, rape is a logical extension of the male role and/ or a response to threatened masculinity, while at the collective level, rape maintains the subservience of women to men. A critical question becomes the following: What are the mechanisms that maintain the current distribution of power, and foster the subordination of women through fear of rape, and silence their voices when rape occurs (Burt, 1991)? The present journal issue suggests that among these mechanisms are social and legal definitions of rape and aspects of the research process.

\section{Definitional Issues}


The articles in this issue by Muehlenhard et al., by Koss, and by Ambrose-Goldberg delineate the impact that different definitions of rape have on decisions regarding the pervasiveness and seriousness of rape. The papers by George et al., Sorenson and Siegel, and Wyatt similarly support the claim that cultural understandings of rape affect the likelihood that an assault will occur, that the victim will recognize it as a crime and will report it, and/or seek post-assault support.

Attempts to synthesize two decades of research on sexual assault in order to discern trends in incidence and prevalence have been plagued by definitional discrepancies. Muehlenhard et al.'s analysis (this issue) of the assumptions and dimensions underlying definitions of sexual assault clarifies the reasons behind the discrepancies. The narrowness or breadth of definitions of rape is shaped strongly by one's acceptance of rape myths (Burt \& Albin, 1981), and this affects the likelihood that an instance of induced sex will be labeled "rape" by victims, perpetrators, and the social and legal communities. An inclusive definition of sexual assault is essential-one that incorporates systematically the means (e.g., verbal coercion, threat of force, use of force) and type of contact (e.g., unwanted contact, attempted or completed penetration with various body parts and objects). Such a definition will enable researchers to demonstrate the scope of sexual assault and also to be specific about which aspect is the focus. An inclusive definition of sexual assault will also allow a focus on either women or men as victims.

Within an inclusive definition, various perspectives are possible, but frequently contradictory. For example, is attempted penile penetration via threat of force more serious than penetration via verbal coercion? Under the law the former is more serious than the latter, but many victims would not agree. Historically, a raped woman was considered "damaged property"; a young woman's virginity was a commodity to be saved for her husband and to be protected by her father in the meantime. Thus, sexual intercourse via any strategy had more serious consequences for a virgin, regardless of the degree of threat or violence, because it spoiled the woman's purity. To take another example, is use of a weapon more serious than not using a weapon? Again, the law says "yes," but many victims would disagree. Stranger rape is more likely to involve use of a weapon and physical force than is acquaintance rape (wife rape being an exception), but Katz (1991) reported data indicating that acquaintance rape victims may be more distressed, and may take longer to feel recovered than victims of stranger rape. Finally, Zilbergeld (1978) suggested that rape is defined from a heterosexual male perspective, which coincides with society's assumption that penile-vaginal intercourse is "real" sex and anything else is "foreplay." This view suggests that forced "real" sex is more serious than any other form of forced sexual contact, but again, victims may have different views of what is traumatic.

\section{Methodological Considerations}

The articles in this journal issue also suggest that the research process itself may support patriarchal, male-centered interpretations of rape. This is due in part to the social influences on the definition of rape, but also to the social nature of the decision-making process involved in conducting research. The ease with which various definitions, scientific methods, and ultimately theories are accepted depends on how well they fit with prevailing cultural beliefs about rape. Until the advent of the women's movement and the development of feminist theories, rape 
research was dominated by male investigators with a clinical viewpoint rather than a social or sociological perspective. Furthermore, much early research focused exclusively on perpetratorsas if the victims and their experiences were essentially irrelevant. The switch to a focus on women, who are the majority of sexual assault victims, served two important purposes. First, the life experiences of women were acknowledged as important, and second, investigation of the experiences and responses of crime victims was legitimated as an area of scientific inquiry. However, we must be careful to avoid the possibility that the recent focus on victims may unwittingly reinforce concepts of victim blame and responsibility. To avoid this, research needs to focus on the context of sexual assault, rather than exclusively on victims or perpetrators.

Cultural understandings of science (Hubbard, 1988) and of rape (White \& Farmer, this issue) shape research questions and the methods employed to address them. What is the impact if researchers conceptualize sexual assault as a crime, or as a mental health problem, or in the context of interpersonal relationships, and frame their methods accordingly? The methods (e.g., paper-and-pencil surveys, telephone interviews, in-person interviews), the samples (e.g., convenience samples of women in treatment or ones who reported the event to the police, vs. random community-based samples, vs. men incarcerated for rape), and the wording of questions (e.g., a single question requiring the respondent to label an experience, vs. behaviorally specific, multiple items) are key determinants of the estimated incidence and prevalence of sexual assault. Incidence and prevalence estimates of sexual assault shape, to some unknown degree, the extent to which sexual assault is viewed as a serious social problem.

White and Farmer's paper (this issue) discusses how variation in research methodologies may lead to distorted views of sexual assault. Analysis of the variables chosen for study often reveals the operation of various cultural assumptions. For example, the predominant focus on features of the victim rather than perpetrator or situational characteristics in attribution research lends itself to a victim-blame interpretation of research findings; that is, it implies that victim characteristics determine the likelihood of rape. By leaving perpetrator and situational characteristics unexplored, researchers may imply that they are unimportant. Similarly, despite the identification of several subtypes of rapists, and inconsistent findings regarding the relationship between sexual aggression and sexual arousal to rape cues (Barbaree \& Marshall, 1991), the past emphasis on physiological sexual arousal patterns among incarcerated rapists supports a biological perspective of rape as a sexual act rather than as violence.

The work reported here reveals several considerations that can improve the quality of future investigations. First, researchers need to acknowledge more fully the implicit assumptions underlying their investigations. Second, researchers need to define sexual assault clearly by specifying the tactics of assault and the type of contact that are the focus of their investigation. Third, more attention must be given to the nature of the samples studied and how they are selected. Fourth, researchers should adopt multiple methods for testing various substantive hypotheses about the causes, correlates, and consequences of sexual assault. Finally, systematic data need to be collected repeatedly so that trends across time can be noted. Only then will we be able to assess the impact of legislative reforms, preventive programs, and other interventions.

\section{Sociocultural Variables}


Until recently there has been little attention to the relationship between sociocultural factors and sexual assault, in part, as George et al. (this issue) indicate, because it is difficult to demonstrate their effects on behavior. However, specific mechanisms have been proposed to account for the effects of culture on sexually coercive behavior. Burkhart and Fromuth (1991) have identified three: (a) gender role socialization patterns and power differentials that normalize rape by advancing rape-supportive beliefs; (b) sexually coercive cognitive schemas and beliefs that encourage the tendency to blame the victim, and reduce the capacity to empathize; and (c) socialsexual interaction scripts that prescribe norms regarding courtship. In this issue, the results of Shotland's analysis of courtship rape, as well as the three epidemiological reports on the prevalence of sexual assault, can be understood in terms of these mechanisms.

Prescriptions for gender roles differ in various cultural groups, and help shape cognitive schemas and courtship scripts. Minority group members appear to perceive rape differently than nonminority groups (Bourque, 1989; Williams \& Holmes, 1981). As Wyatt (this issue) suggests, the passing of rape stories from one generation to the next may be a kind of family or cultural ritual, keeping a particular view alive across time. These stories may fade with acculturation into the dominant culture, but their remnants persist as myths-e.g., a black woman cannot be raped; an Hispanic man is "one who can drink more, defend himself best, have more sex relations, and have more sons borne by his wife" (Madsen, 1973, p. 22).

The historical context of various ethnic groups in this country provides the first set of clues regarding perceptions of appropriate male-female behavior. Donat and D'Emilio (this issue) and Wyatt (this issue) discuss the historical meaning of rape for African American women. Various myths about Black sexuality arose during the enslavement of African Americans and persist to this day. It is not surprising that African American women's experience of rape (if not the actual likelihood) differs from that of White women. According to Wyatt, African American victims of sexual assault are more likely than White victims to be single, to have experienced more attempted rapes, and to be attacked by strangers. Furthermore, fewer are likely to disclose the attack to police and to receive social support, whereas more are likely to make external attributions to the situation as a causal factor.

Sorenson and Siegel (this issue) suggest that the cultural milieu of Hispanics, i.e., strong family ties and religious values, may help reduce the likelihood of sexual victimization among Hispanic women, especially those born in Mexico in contrast to those born in the United States. Fischer (1987) has indicated that bicultural and bilingual Hispanic women's exposure to the less restrictive sex roles of the majority culture results in their having fewer negative attitudes toward date rape than other Hispanic women. George et al. (this issue) mention the possibility that traditional patriarchal values help protect southern women, especially rural ones, from assault. This is not, however, an argument for reasserting patriarchal values. As Donat and D'Emilio (this issue) discussed, these traditional values see a woman's sexuality as a property of men (her father or husband) and one that must be protected. As a result, women are not free to express their sexuality in individual ways, but must behave within traditional roles for feminine conduct. Social change appears to be accompanied by higher levels of sexual violence toward women.

The higher level of sexual assault among younger women, better educated women, urban women, and U.S.-born Hispanic women (in comparison to Mexican-born Hispanic women) is 
distressing, and merits further investigation. Each of these groups of women has gained access to some of the benefits of the dominant culture (i.e., education and employment opportunities), yet they continue to be denied full-status membership (including respect and acceptance as equals). Because the historical and cultural foundations of women's status and norms regarding their sexuality are highly resistant to change, women remain acceptable targets of violence. In addition to transforming views of women, we need to identify mechanisms to ameliorate the problems such as these that are created by social change.

\section{Mechanisms for Social Change}

Past efforts aimed at social change and rape prevention have focused on legal reforms in definitions of rape, rules of evidence, and the statutory age, as well as control of obscenity in the media. These reforms were based on the assumptions that stricter sanctions would reduce the likelihood of perpetrating a crime and that pornography plays a causal role in rape. However, both Linz et al. and Ambrose-Goldberg in this issue raise doubts about the value of legal reform in the absence of widespread educational programs. They note that educational efforts can be aimed at several levels: the individual, the institutional, and the broad societal level. The emerging view is that if we cannot change the attitudes and values of individuals-media consumers, judges and jurors, women and men who are involved in personal relationships-the impact of various legal reforms will remain limited.

\section{Conclusion}

In the past 20 years, models of sexual assault have moved from stressing psychopathology in the attributes of victims and perpetrators, to multidimensional models emphasizing the interaction of sociocultural, interpersonal, and intrapersonal factors. It is now recognized that rape is more likely to be committed by an acquaintance, frequently in the context of a developing or ongoing relationship, than by a stranger lurking in bushes under the cover of darkness. The increased concern with sociocultural factors has been evident throughout this journal issue. In this issue, Donat and D'Emilio have placed views of sexual assault within a sociohistorical context; Muehlenhard et al. identified the social nature of definitions of sexual assault; White and Farmer noted the influence of cultural values and assumptions about rape and research on the research process; and Koss called for community-based epidemiological studies. The three papers reporting data on sexual experiences as a function of ethnicity and geographic locale illuminated the relevance of cultural and subcultural considerations. Similarly, Shotland's discussion of the relationship status and level of previous intimacy as factors in sexual assault, and Linz et al. 's and Goldberg-Ambrose's description of roles of the media and judicial reform in assault prevention and public education, also attest to the importance of a sociocultural perspective.

Researchers are challenged to conduct research for victims, with the ultimate goal being the eradication of sexual assault against women and girls, men and boys. Sexual assault occurs in a sociocultural context that affects the victim's, perpetrator's, and society's understanding of, reaction to, and tolerance for the event. Therefore, researchers should incorporate a sociocultural perspective into their assumptions, questions, methods, analyses, and ultimately their theories. 
Scientific investigations of sexual assault occur within a social atmosphere of urgency. A more thorough knowledge of the incidence and prevalence of sexual assault, the correlates of its occurrence, and it consequences will allow women and men to develop more effective interventions and preventive countermeasures. Scientific research is one step in the process of developing a healthier world for women and men. In tum, social action, informed by a sociocultural perspective, can lead to realizing the full potential of scientific findings.

\section{References}

Barbaree, H. E., \& Marshall, W. L. (1991). The role of male sexual arousal in rape: Six models. Journal of Consulting and Clinical Psychology, 59, 621-630.

Bourque, L. B. (1989). Defining rape. Durham, NC: Duke University Press.

Burkhart, B. R., \& Fromuth, M. E. (1991). Individual and social psychological understandings of sexual coercion. In E. Gruerholz \& M. A. Koralewski (Eds.), Sexual coercion: A sourcebook on its nature, causes, and prevention (pp. 75-89). Lexington, MA: Lexington Books.

Burt. M. R. ( 1980). Cultural myths and support for rape. Journal of Personality and Social Psychology, 38, 217-230.

Burt. M. R. (1991). Rape myths and acquaintance rape. In A. Parrot \& L. Bechhofer (Eds.), Acquaintance rape: The hidden crime. New York: Wiley.

Burt, M. R., \& Albin, R. S. (1981). Rape myths, rape definitions, and probability of conviction. Journal of Applied Social Psychology, JJ, 212-230.

Feild, H. S. (1978). Attitudes toward rape: A comparative analysis of police, rapists, crisis counselors, and citizens, Journal of Personality and Social Psychology, 36, 156-179.

Fischer, G. ( 1987). Hispanic and majority student attitudes toward forcible date rape as a function of differences in attitudes toward women. Sex Roles, 17, 93-101.

Greensboro News \& Record. (1991, May 13). Accuser's privacy as stake. P. A3.

Harney, P. A., \& Muehlenhard, C. L. ( 1991 ). Factors that increase the likelihood of victimization. In A. Parrot \& L. Bechhofer (Eds.), Acquaintance rape: The hidden crime (pp. 159-175). New York: Wiley.

Hubbard, R. (1988). Some thoughts about the masculinity of the natural sciences. In M. M. Gergen (Ed.), Feminist thought and the structure of knowledge. New York: New York University Press.

Jaffe, D., \& Straus, M. A. ( 1987). Sexual climate and reported rape: A state-level analysis. Archives of Sexual Behavior, 16, 107-123. 
Katz, B. L. (I 991 ). The psychological impact of stranger versus nonstranger rape on victims' recovery. In A. Parrot \& L. Bechhofer (Eds.), Acquaintance rape: The hidden crime (pp. 251269). New York: Wiley.

Madsen, W. (1973). The Mexican-Americans of South Texas (2nd ed.). New York: Holt, Rinehart \& Winston.

Mandoki, C. A., \& Burkhart, B. R. (1991). Women as victims: Antecedents and consequences of acquaintance rape. In A. Parrot \& L. Bechhofer (Eds.), Acquaintance rape: The hidden crime (pp. 176-191). New York: Wiley.

Plummer, K. (1981). The social uses of sexuality: Symbolic interaction, power, and rape. In J. Hopkins (Ed.), Perspectives on rape and sexual assault (pp. 37-55). London: Harper \& Row.

Sanday, P. R. (1981 ). The socio-cultural context of rape: A cross-cultural study. Journal of Social Issues, 37(4), 5-27.

Williams, J. E., \& Holmes, K. A. (1981 ). The second assault: Rape and public attitudes. Westport, CT: Greenwood.

Zilbergeld, B. (1978). Male sexuality: A guide to sexual fulfillment. New York: Bantam. 